\title{
Population Health and the Pandemic: Emerging Stronger Next Time.
}

David B. Nash

Thomas Jefferson University

Follow this and additional works at: https://jdc.jefferson.edu/healthpolicyfaculty

Part of the Infectious Disease Commons, and the Public Health Commons Let us know how access to this document benefits you

\section{Recommended Citation}

Nash, David B., "Population Health and the Pandemic: Emerging Stronger Next Time." (2020). College of Population Health Faculty Papers. Paper 105.

https://jdc.jefferson.edu/healthpolicyfaculty/105

This Article is brought to you for free and open access by the Jefferson Digital Commons. The Jefferson Digital Commons is a service of Thomas Jefferson University's Center for Teaching and Learning (CTL). The Commons is a showcase for Jefferson books and journals, peer-reviewed scholarly publications, unique historical collections from the University archives, and teaching tools. The Jefferson Digital Commons allows researchers and interested readers anywhere in the world to learn about and keep up to date with Jefferson scholarship. This article has been accepted for inclusion in College of Population Health Faculty Papers by an authorized administrator of the Jefferson Digital Commons. For more information, please contact: JeffersonDigitalCommons@jefferson.edu. 


\title{
Population Health and the Pandemic: Emerging Stronger Next Time
}

\author{
David B. Nash, MD, MBA
}

Keywords: population health, systems thinking, social determinants, untold burden

A LONG WITH OUR entire editorial board and the team at Mary Anne Liebert, I am very proud to bring you this dedicated issue of Population Health Management focusing on the current COVID-19 pandemic. Our journal is in a unique position to deliver new insights and new tools with which to tackle the pandemic from a nonclinical perspective.

Our perspective is focused on the glaring inequities in the system, the disproportionate negative impact of the pandemic on all minority communities, the pernicious nature of our reimbursement system that has led to thousands of hospital layoffs exactly at a time when we should be bolstering our health system, and the role of population health management in tackling the social determinants of health.

Our mission, in part, is to disseminate new insights gleaned from the tsunami of data about COVID-19 and then to apply these insights to improve health. We also will strengthen our society to be better prepared for the inevitable next surge. In sum, we will focus on a systems approach to battling the pandemic.

To fulfill this mission, we have assembled this dedicated issue that includes editorial commentary in the form of several "Points of View" (POVs), original research articles, and summaries of 2 expert roundtables featuring leaders from across the nation. While all the authors have contributed to a better understanding of the nonclinical aspects of COVID-19, several threads tie their disparate contributions together, including the application of systems thinking, the use of population health intelligence (artificial intelligence and predictive analytics), deep analysis of social media postings, and embracing key learnings from other industries.

The first POV is from a team at Huron Consulting who noted that COVID-19 will drive 3 changes in the near term, including "compelling provider organizations to act more as a system, transforming the care model to achieve the Quadruple Aim, and ensuring that care is organized around the consumer." The team from Huron was able to draw on their work with integrated delivery systems nationwide.

A second POV, from a relatively new artificial intelligence start-up firm called HealthPrecision, focused on how we might embrace learnings from other industries, such as the concept of human factors engineering in the cockpit of an airplane and its relevance to identifying risks of health deterioration and gaps and errors in clinical care. It begs the question: Will the health care system be self-reflective and therefore attempt to learn from the mistakes we made during the height of the pandemic?

The final POV presents an important algorithm to potentially guide employers toward a safe return-to-work policy, with a special emphasis on antibody testing for COVID-19. This POV represents a distillation of work from multiple private organizations including, for example, Humana, Quest, Express Scripts, and Walgreens, among others, and therefore could be the basis of a national model.

One of the original research articles features work from a team of social scientists who created a customized analytic engine, using both machine learning and natural language processing, to quickly extract information from social media channels to further explore what persons with COVID-19 were talking about regarding their symptoms and disease progression. The authors were then able to offer novel insights into patient experiences as a source of real-world data.

In another article, a team of physicians from Microsoft describe the use of new technology in the public health battle against COVID-19. One intriguing example was their use of sophisticated "chatbots" that can effectively triage patient pandemic-related inquiries at scale, thereby greatly expanding the number of persons who can access and act on new diseaserelated data. Patients can then make better informed decisions with regard to possible hospitalization versus remaining at home, for example.

In a third article, a global team from Kantar Health evaluated emerging inequities in the use of rapidly expanding telehealth services. By merging insurance claims data and patient-related outcome measures, they demonstrated that glaring disparities remain with regard to access to telehealth services for certain populations.

A fourth article, by myself and colleagues, explored a wide range of impacts on the health care system related to

Jefferson College of Population Health, Philadelphia, Pennsylvania, USA. 
the mandatory closure of all elective visits and procedures for nearly 3 months. We were able to document a profound impact on the health of the population in one major metropolitan area, along with important implications for future system reform.

Two roundtables close out the special issue. The first roundtable focused on the gaping holes in the health care system that were exposed during the pandemic, such as lack of universal access and universal coverage. Six national experts also tackled the complex issues surrounding institutional racism in the delivery system and options for improvement. The second roundtable, with another 5 national experts, discussed several tactical issues post pandemic, including how we might overcome patient fears about returning for needed preventive services, harnessing telehealth for minority populations, and improving workforce preparedness for the near future.

I want to thank all of the authors for their important contributions to this dedicated issue of our journal, and the myriad peer reviewers who provided helpful comments to the authors that invariably strengthened the manuscripts. I want to give special thanks to our amazing Managing Editor, Ms. Deborah Meiris, whose tenacity, attention to detail, and professionalism help make our journal essential reading during this tumultuous time. Finally, I want to thank
Ms. Jennifer Kuhn, from our publisher, Mary Ann Liebert, for all of her support and especially her help in organizing the 2 nationally representative roundtable discussions.

Improving the health of the population has never been more important than today. On behalf of the entire editorial board, the authors, the peer reviewers, and our publisher, my heartfelt thanks to all of our readers. Your feedback on any aspect of this dedicated issue is most welcome.

\section{Author Disclosure Statement}

The author declares that there are no conflicts of interest.

\section{Funding Information}

No funding was received for this editorial.

\author{
Address correspondence to: \\ David B. Nash, MD, MBA \\ Jefferson College of Population Health \\ 901 Walnut Street, 10th floor \\ Philadelphia, PA 19107 \\ USA
}

E-mail: david.nash@jefferson.edu 